\title{
An alternative method to create a breast mound after tissue expander insertion: The modified Goldilocks technique
}

Dong Nyeok Jeon, Kyunghyun Min, Hyun Ho Han

Department of Plastic Surgery, Asan Medical Center, University of Ulsan College of Medicine, Seoul, Korea
With the recent increase in reported cases of breast implant-associated anaplastic large cell lymphoma (BIA-ALCL), fears of breast implants have increased. In particular, some patients now desire expander removal without implant insertion. In the case described herein, a 41-year-old female patient who had undergone a skin-sparing mastectomy with expander insertion due to breast cancer requested expander removal due to fear of BIA-ALCL during expansion. The authors modified the Goldilocks technique to prevent a chest wall deformity due to expansion. The expanded skin was sufficiently thick, as it was engrafted with acellular dermal matrix, and some of it was de-epithelized and rolled in. The patient's chest wall depression was completely corrected and an acceptable breast mound was created. To summarize, this technique was used to correct a chest wall deformity and to form a breast mound in a patient who underwent expander removal without implant insertion.

Keywords Acellular dermis / Tissue expansion devices / Breast implant / Breast mound

\section{INTRODUCTION}

There are many ways to perform breast reconstruction after mastectomy, such as a two-stage operation using a tissue expander, filling the breast volume with autologous tissue, or immediate implant insertion. Tissue expander-based two-stage operations are widely used along with skin-sparing mastectomy or contralateral augmentation [1-3]. However, expansion may fail to occur as desired, or the patient may elect to have the expander removed without replacing it with an implant. Recently, as breast implant-associated anaplastic large cell lymphoma (BIA-ALCL)-related concerns have grown, patients fearing BIA-ALCL have been requesting expander removal without implant insertion [4-6].

Received: Mar 25, 2020 Revised: May 12, 2020 Accepted: May 17, 2020 Correspondence: Hyun Ho Han Department of Plastic Surgery, Asan Medical Center, University of Ulsan College of Medicine, 88 Olympic-ro 43-gil, Songpa-gu, Seoul 05505, Korea

Tel: +82-2-3010-3602, Fax: +82-2-476-7471, E-mail: tripleh1952@gmail.com

Copyright () 2020 The Korean Society for Aesthetic Plastic Surgery.

This is an Open Access article distributed under the terms of the Creative Commons Attribution Non-Commercial License (https://creativecommons.org/licenses/by-nc/4.0/) which permits unrestricted non-commercial use, distribution, and reproduction in any medium, provided the original work is properly cited. www.e-aaps.org
In these cases, an area of concern for the surgeon is manipulation of the skin flap that has already been expanded. In particular, the base tissue of the expander often has a depression deformity due to the pressure of the expander. If only expander removal is done, with no implant insertion, the chest wall may look more concave than is the case immediately after mastectomy [7,8]. Here, we present a surgical technique that can be considered for patients who request only expander removal, and do not want the expander to be exchanged for an implant.

\section{CASE REPORT}

A 41-year-old woman underwent skin-sparing mastectomy due to breast cancer (stage 3a, T2N1M0). The mastectomy volume was $141 \mathrm{~mL}$ and immediate breast reconstruction was performed using a $275 \mathrm{~mL}$ tissue expander (Mentor Worldwide LLC, Irvine, CA, USA) and Megaderm (L\&C Bio Co., Ltd., Seongnam, Korea). At that time, the patient underwent an expander-based two-stage operation with contralateral breast augmentation. The tissue expander volume was $250 \mathrm{~mL}$ at the end of expansion (Fig. 1).

Periodic tissue expansion was performed, but the patient did not want an implant to be inserted after the expander was removed due to concerns regarding BIA-ALCL, which stemmed from the 
first report of a patient with BIA-ALCL in Korea [9]. The expander was removed without implant placement, as requested by the patient, but the depression deformity of the chest wall was prominent, and the expanded skin was used to compensate for the depression.

The expanded skin was maintained at a thickness of $2-3 \mathrm{~mm}$. The remaining skin of the patient was temporarily closed with
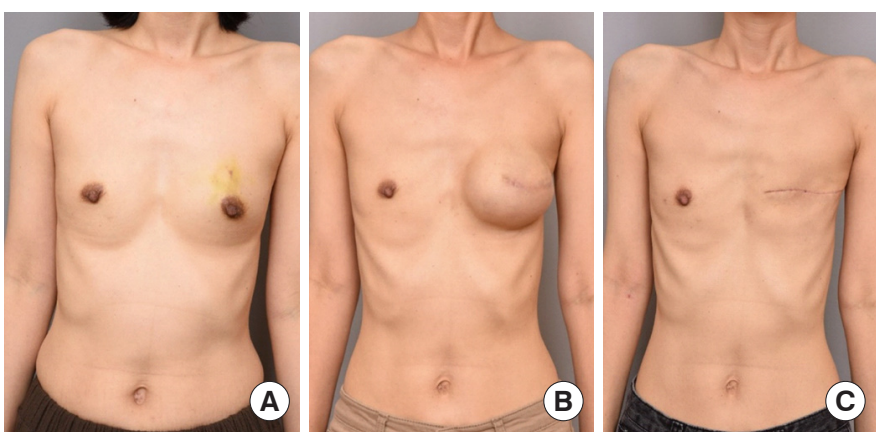

Fig. 1. Clinical photographs. (A) Preoperative clinical photograph. (B) After tissue expansion ( $250 \mathrm{~mL}$, left breast). (C) Postoperative 2 months. maximum approximation, and all remaining skin was de-epithelialized and rolled from the outside of the skin into the inside (Figs. $2,3)$. This method is similar to the previously reported Goldilocks technique, with a slight modification to the upper pole skin to add volume $[10,11]$. After skin closure, the patient's depression was completely corrected and it was possible to create a breast mound, although it was relatively low.

\section{DISCUSSION}

A small number of patients who have had a tissue expander inserted in the initial stage of two-stage reconstruction may elect to have the tissue expander removed without exchanging it with a permanent implant. Patients may make this decision to avoid the multiple complications that may occur after permanent implant insertion. Recent reports of BIA-ALCL in patients who underwent textured implant insertion have amplified fears regarding implants [4,5]. In this case, we removed the tissue expander after the patient elected not to proceed with a permanent implant, and we addressed the already expanded skin region by using the modified Goldilocks
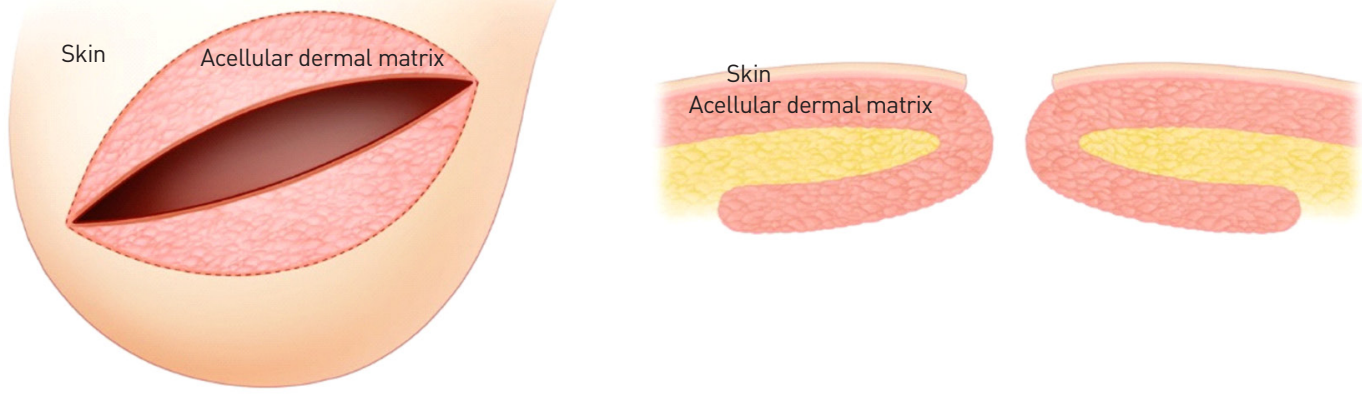

Fig. 2. (A) The expanded skin with the acellular dermal matrix after de-epithelization. (B) Rolling in and approximation of the remaining skin.
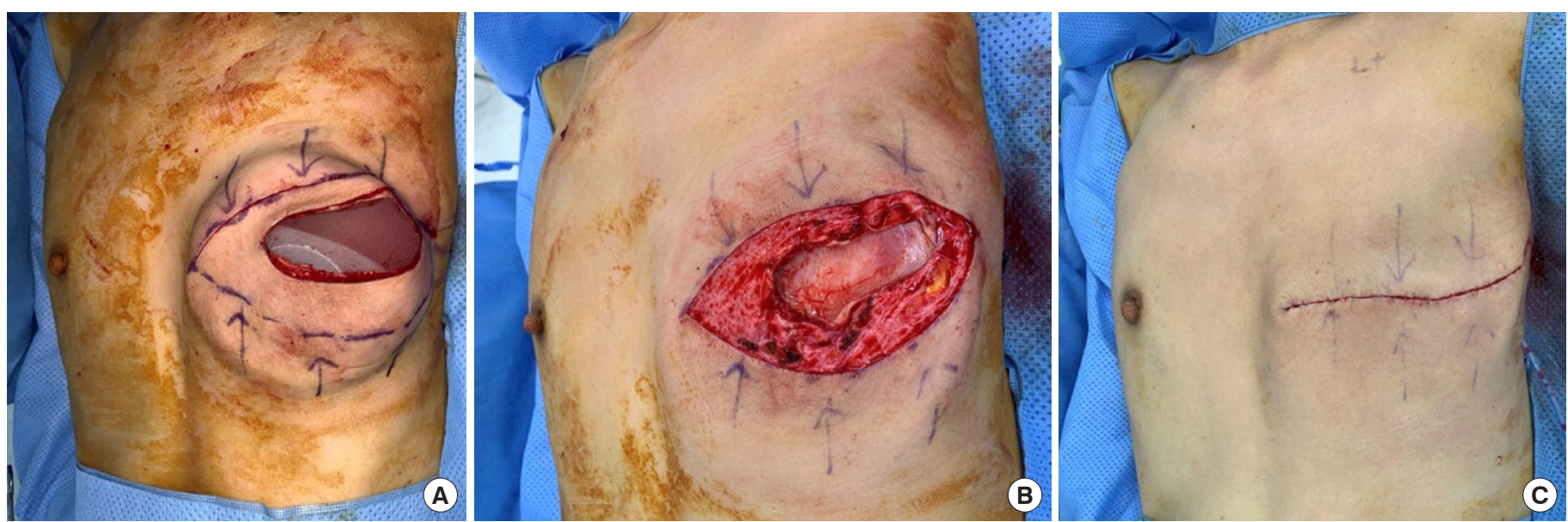

Fig. 3. Intraoperative photographs. (A) Design of the modified Goldilocks technique. (B) De-epithelization of the remaining skin flap. (C) Postoperative photograph. 
technique $[10,11]$.

If breast reconstruction is not successfully performed with a prosthetic implant, this technique can be used to construct a breast mound and to prepare the tissue for secondary surgery. If a patient with a tissue expander refuses a permanent implant due to implantrelated fears, the expanded skin tissue can be used to minimize or prevent chest wall deformation as described. Generally, the depression of the bone during expansion tends to normalize within 2 to 3 months after expander removal [12]. However, because the volume of the breast compared to the contralateral side is insufficient, as much as tissue as possible should be maintained to minimize the imbalance of the chest and to prepare for future reconstruction. In particular, the expanded breast skin may already have been engrafted by application of acellular dermal matrix when the expander was inserted. If used, such tissue may have more sufficient thickness and quality than expected.

However, rolling up the expanded skin for tissue supplementation to create a breast mound may raise concerns about oncologic safety. However, there is no need to worry about cancer recurrence in the skin that remains post-mastectomy, as the oncologic safety of nipple-areolar skin-sparing mastectomy has been proven and widely accepted [13-15]. If a general surgeon performs mastectomy and confirms that the resection margins are free of cancer, this technique may be considered safe on the basis of the evidence to date.

In conclusion, this modified Goldilocks technique is the best way to minimize a chest wall concave deformity and to form a breast mound when a tissue expander is removed without implant insertion. In particular, previously inserted acellular dermal matrix, if present, can be used for tissue supplementation. The safety of this technique has also been proven, and it seems to be a technique with sufficient merits to be worth trying.

\section{NOTES}

\section{Conflict of interest}

No potential conflict of interest relevant to this article was reported.

\section{Ethical approval}

The study was performed in accordance with the principles of the Declaration of Helsinki.

\section{Patient consent}

The patient provided written informed consent for the publication and the use of her images.

\section{ORCID}

Dong Nyeok Jeon

Kyunghyun Min

Hyun Ho Han

\section{REFERENCES}

1. Castello JR, Garro L, Najera A, et al. Immediate breast reconstruction in two stages using anatomical tissue expansion. Scand J Plast Reconstr Surg Hand Surg 2000;34:167-71.

2. Cordeiro PG, McCarthy CM. A single surgeon's 12-year experience with tissue expander/implant breast reconstruction: part I. A prospective analysis of early complications. Plast Reconstr Surg 2006;118:825-31.

3. Schuster RH, Rotter S, Boonn W, et al. The use of tissue expanders in immediate breast reconstruction following mastectomy for cancer. $\mathrm{Br}$ J Plast Surg 1990;43:413-8.

4. Marra A, Viale G, Pileri SA, et al. Breast implant-associated anaplastic large cell lymphoma: a comprehensive review. Cancer Treat Rev 2020; 84:101963.

5. Nava MB, Adams WP Jr, Botti G, et al. MBN 2016 Aesthetic Breast Meeting BIA-ALCL Consensus Conference Report. Plast Reconstr Surg 2018;141:40-8.

6. Roberts JM, Carr LW, Jones A, et al. A prospective approach to inform and treat 1340 patients at risk for BIA-ALCL. Plast Reconstr Surg 2019; 144:46-54.

7. Makiguchi T, Atomura D, Nakamura H, et al. Quantitative assessment and risk factors for chest wall deformity resulting from tissue expansion for breast reconstruction. Breast Cancer 2019;26:446-51.

8. Sinow JD, Halvorsen RA Jr, Matts JP, et al. Chest-wall deformity after tissue expansion for breast reconstruction. Plast Reconstr Surg 1991;88: 998-1004.

9. Ministry of Food and Drug Safety. Report of breast implant-associated anaplastic large cell lymphoma (BIA-ALCL) in Korea [Internet]. Cheongju: Ministry of Food and Drug Safety; c2019 [cited 2020 Mar 7]. Available from: https://www.mfds.go.kr/brd/m_99/view.do?seq=43641\&src $\mathrm{hFr}=\& \operatorname{srchTo}=\& \operatorname{srchWord}=\& \operatorname{srchTp}=\& i t m \_s e q \_1=0 \& i t m \_s e q \_2=$ 0\&multi_itm_seq=0\&company_cd=\&company_nm=\&page $=1$.

10. Schwartz JD, Skowronksi PP. Extending the indications for autologous breast reconstruction using a two-stage modified goldilocks procedure: a case report. Breast J 2017;23:344-7.

11. Zavala KJ, Kwon JG, Han HH, et al. The Goldilocks technique: an alternative method to construct a breast mound after prosthetic breast reconstruction failure. Arch Plast Surg 2019;46:475-9.

12. Gurtner GC, Neligan PC. Plastic surgery e-book: volume 1. principles. New York: Elsevier Health Sciences; 2017.

13. Agha RA, Al Omran Y, Wellstead G, et al. Systematic review of therapeutic nipple-sparing versus skin-sparing mastectomy. BJS Open 2018; 3:135-45.

14. Margenthaler JA, Gan C, Yan Y, et al. Oncologic safety and outcomes in patients undergoing nipple-sparing mastectomy. J Am Coll Surg 2020;230:535-41.

15. Odom EB, Parikh RP, Um G, et al. Nipple-sparing mastectomy incisions for cancer extirpation prospective cohort trial: perfusion, complications, and patient outcomes. Plast Reconstr Surg 2018;142:13-26. 